\title{
Central Venous Catheter Complications during Home Parenteral Nutrition: A Prospective Pilot Study of 481 Patients with More than 30,000 Catheter Days
}

\author{
Alexander Crispin ${ }^{\mathrm{a}} \quad$ Paul Thul $^{\mathrm{b}} \quad$ Dirk Arnold $^{\mathrm{c}}$ Sandra Schild $^{\mathrm{d}}$ Arved Weimann $^{\mathrm{e}}$ \\ a IBE Lehrstuhl für Biometrie und Bioinformatik, Ludwig-Maximilians-Universität München, \\ ${ }^{b}$ Klinik- für Allgemein-, Visceral-, Gefäß- und Thoraxchirurgie, Charité Berlin, \\ ${ }^{c}$ Klinik für Innere Medizin IV (Hämatologie und Onkologie), Universität Halle-Wittenberg, \\ dTravacare $\mathrm{GmbH}$, Hallbergmoos, \\ e Klinik für Allgemein-und Visceralchirurgie, Städtisches Klinikum St. Georg, Leipzig, Germany
}

\section{Key Words}

Central venous catheter complications .

Home parenteral nutrition - Multicentre study

\section{Summary}

Background: Home parenteral nutrition (HPN) has been shown to delay deterioration in cancer patients with malnutrition. Its risk-benefit ratio, however, is determined by the threat of central venous catheter (CVC) complications. Only few prospective studies on this subject exist, most of them based on small samples. The objective of this study was to provide reliable estimates of incidence rates of CVC complications in everyday HPN patient care in Germany. Patients and Methods: Aiming for a large prospective cohort study, we cooperated with a service provider caring for HPN patients nationwide. Between July 1 and November 30, 2006, all consecutive adult patients with more than 10 infusion days and no previous history of HPN were recruited. Follow-up ended on January 31, 2007. Data were collected in a standardised way by the provider's staff. To prevent underreporting, we used computer-assisted telephone interviews with medical caregivers as a provider-independent data source. Results: 481 patients met the inclusion criteria, contributing a total of 31,337 catheter days. 52 patients experienced a total of 63 CVC complications, resulting in an incidence rate of $2.01 \mathrm{CVC}$ complications per 1,000 catheter days including 1.02 CVC infections per 1,000 catheter days. Conclusion: HPN administration can be safely performed with a relatively low rate of CVC complications.
Schlüsselwörter

Zentralvenöse Katheter, Komplikationen .

Heimparenterale Ernährung · Multicenter-Studie

\section{Zusammenfassung}

Hintergrund: Bei Tumorpatienten mit Mangelernährung kann eine heimparenterale Ernährungstherapie (HPE) eine Verschlechterung des Erkrankungsverlaufs hinauszögern. Das Risiko-Nutzen-Verhältnis ist durch die Gefahr einer Komplikation seitens des zentralvenösen Katheters (ZVK) bestimmt. Wenige Studien, oftmals basierend auf kleinen Stichproben, haben sich mit dieser Thematik bisher beschäftigt. Ziel unserer Studie war es, eine reliable Bestimmung der Inzidenz von ZVK-Komplikationen in der täglichen HPE-Patientenversorgung in Deutschland zu ermitteln. Patienten und Methoden: Um eine große prospektive Kohorten-Studie realisieren zu können, kooperierten wir mit einem deutschlandweit arbeitenden HPEDienstleister. Zwischen dem 1. Juli und dem 30. November 2006 wurden konsekutiv alle volljährigen Patienten mit mehr als 10 Infusionstagen und keiner HPE in der Vorgeschichte rekrutiert. Das Follow-up wurde bis einschließlich 31. Januar 2007 durchgeführt. Die Datenerhebung erfolgte durch eine standardisierte Erhebung durch die Mitarbeiter des Dienstleisters und, um eine zu niedrige Melderate auszuschließen, durch vom Versorger unabhängige Telefoninterviews mit den beteiligten medizinischen Fachkräften. Ergebnisse: 481 Patienten erfüllten die Einschlusskriterien, die eine Gesamtsumme von 31337 Kathetertagen unter Beobachtung einbrachten. 52 Patienten erlitten insgesamt 63 ZVK-Komplikationen, so dass eine Inzidenzrate von 2,01 ZVK-Komplikationen pro 1000 Kathetertagen und 1,02 ZVK-Infektionen pro 1000 Kathetertagen ermittelt wurde. Schlussfolgerung: Die HPE kann mit einer relativ niedrigen Rate an ZVK-Komplikationen verabreicht werden.

Dr. med. Alexander Crispin, MPH

Marchioninistraße 15, 81377 München, Germany

Tel. +49 89 7095-4498, Fax -7491

cri@ibe.med.uni-muenchen.de 


\section{Introduction}

Malnutrition is frequently observed in chronic and severe disease, and is associated with impaired outcome [1-3]. In German hospitals, every 4th patient is malnourished. In oncology departments, malnutrition has been found in $38 \%$ of the patients [4]. The survival of an incurable cancer patient is not only limited by the tumour itself but also by malnutrition [5]. Home parenteral nutrition (HPN) is widely used to delay or correct malnutrition both in oncological and non-oncological patients $[6,7]$. Its risk-benefit ratio, however, is related to the threat of central venous catheter (CVC) complications.

In the largest European study [8], CVC-related complications were observed in $25 \%$ of all HPN patients with mostly benign indications and long-term HPN care. 50\% of the reported complications were catheter infections, resulting in an incidence of 0.6 infections per 1,000 catheter days. Other international studies reported CVC complication rates between 0.94 and 5.56 per 1,000 catheter days and catheter infection rates between 0.6 and 5.36 per 1,000 catheter days [9-21]. All these studies had some methodological limitations, as only few were prospective, and most were based on small samples of predominantly non-oncological patients from single specialised medical centres.

In May 2007, the Deutsche Gesellschaft für Ernährungsmedizin e.V. (DGEM) published guidelines for parenteral nutrition and emphasised the necessity of monitoring the HPN therapy for complications and effectiveness [22]. Unlike in Denmark, France, or Scotland, in Germany there is no central surveillance of HPN therapy. HPN is managed by many different agencies, including therapy-initiating physicians, general practitioners, outpatient nursing services, HPN providers, and the patients themselves without any central standard. To our knowledge, no large prospective study of the occurrence of CVCrelated complications in HPN patients in Germany exists. Therefore, the aim of our study was to provide an estimate of the incidence of CVC complications in everyday HPN patient care under the conditions of the German healthcare system.

\section{Patients and Methods}

\section{Patients and Data Collection}

To achieve a large prospective cohort study, we cooperated with a service provider caring for HPN patients nationwide (Travacare $\mathrm{GmbH}$, Hallbergmoos, Germany). Between July 1 and November 30, 2006, all consecutive adult patients of the provider with more than 10 infusion days after hospital discharge and no previous history of HPN were recruited. There were no restrictions regarding diagnosis, indication, expected survival, and planned duration of HPN. Informed consent was signed during the first 10 infusion days at home. A total of 481 patients from 181 centres were included (fig. 1). Follow-up lasted until January 31, 2007. The study was approved by the Ethics Committee of the Medical Faculty of the Ludwig Maximilians University Munich.

Data were collected during monthly patient visits by the provider's staff, using standardised case report forms (CRF) and following standard operating procedures. Besides providing general demographic data including age, gender, primary diagnosis, and reason for HPN, patients were intervie-

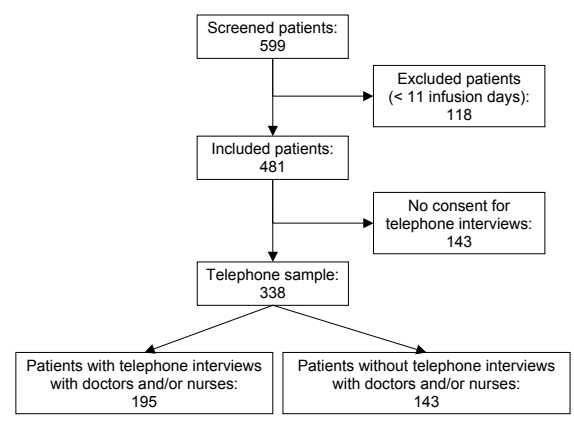

wed at each visit regarding abnormalities in appetite, thirst, and excretion as well as the presence of nausea, vomiting, head- or backache, ascites, or symptoms of catheter complications (e.g. temperature, fever, shivering, infusion abnormalities, exudation, pain, turgor, redness, bleeding close to the catheter). In the time between the visits, patients and outpatient nursing staff could use a memory aid document ('patient's passport') to record abnormalities. Entries in these documents were copied to the official CRF during the next visit. Symptoms indicative of CVC complications were recorded by the provider's staff and corroborated with the patients' attending physicians. Complications were recorded as local infection, systemic infection, CVC obstruction, CVC dislocation, CVC defect, other CVC complication, and/or CVC removal in consequence of a complication.

To prevent underreporting, face-to-face data collection was complemented by a second provider-independent information source. This was established in form of computer-assisted (and thus highly standardised) telephone interviews (CATI) with patients, outpatient nursing personnel, general practitioners, and therapy-initiating physicians. $70.3 \%$ of all patients recruited gave written consent to these interviews. The interviews were carried out by a specially trained postgraduate public health student at the Department of Medical Informatics, Biometry, and Epidemiology (IBE) of the Ludwig Maximilians University Munich. Contacts with patients and professional caregivers (outpatient nursing personnel, general practitioners, therapy-initiating physicians) were attempted (up to 5 times) in the order of patient recruitment after a minimum of 12 therapy days. A second interview was attempted 4 weeks later. Professionals were asked if and when any of the above CVC complications had occurred and whether the diagnosis was assured. If so, the complication was counted regardless of CRF information recorded during the patient visits. After HPN termination, telephone interviews were performed to investigate the patient's life-status and the cause of death in case of fatal outcomes. Patient interviews were used to trigger additional professional interviews in the case of suspected complications. To minimise the risk of CVC complications, the provider's staff educated patients and outpatient nursing personnel in using a highly structured manual containing text, pictures, and the manufacturers' instructions to illustrate the correct process of preparing the infusion and thus assure aseptic handling even without the use of gloves and gowns. The following parameters were considered as potential risk factors for the incidence of CVC complications: the type of catheter (port system, Broviac/Hickman catheter, other), the use of an infusion pump, the HPN frequency per week, the frequency of dressing and needle changes, the caregiver in charge of dressing and needle changes (patient or a relative, outpatient nursing service, specialised provider), and the use of the patient's catheter for other intravenous therapies beside HPN. To get information about the effect of the HPN therapy, the infusion regimen, the infusion days per week, and the weight during the HPN were recorded.

\section{Statistical Analysis}

Descriptive statistics were computed for all variables using adequate measures of location and dispersion. Incidence rates of catheter complications were expressed as events per 1,000 catheter days with $95 \%$ confidence in- 
Table 1. Patient characteristics at baseline $(n=481)$

\begin{tabular}{lc}
\hline Characteristics & Mean (range) \\
\hline Age, years & $65(20-92)$ \\
Height, $\mathrm{m}$ & $168(125-197)$ \\
Weight, kg & $58(25-120)$ \\
Body mass index, $\mathrm{kg} / \mathrm{m}^{2}$ & $20.5(11.8-36.2)$ \\
Time since catheter implantation, days & $212(10-2,490)$ \\
Duration of HPN, days & $65(11-194)$ \\
\cline { 2 - 2 } & Patients, n (\%) \\
\cline { 2 - 2 } Male sex & $203(42.2)$ \\
Underlying diagnosis & \\
Cancer & $441(91.7)$ \\
Other & $20(4.1)$ \\
Not given & $20(4.2)$ \\
Indications for HPN & \\
Malabsorption & $287(59.7)$ \\
Short bowel syndrome & $16(3.3)$ \\
Chronic ileus & $4(0.8)$ \\
Other & $26(5.4)$ \\
Not given & $148(30.8)$ \\
Port & \\
Other & $454(94.4)$ \\
\hline & \\
&
\end{tabular}

$\mathrm{HPN}=$ Home parenteral nutrition

tervals (CI). Exploration of potential risk factors was based on Cox proportional hazards models modelling the time until the patient's first complication. Analyses were carried out using SAS 9.1 for Linux (SAS Institute, Cary, NC, USA).

\section{Results}

\section{Patient Characteristics and Data of HPN Use}

Between July and November 2006, a total of 481 patients were recruited, predominantly elderly patients with malignancies and with port systems (table 1). The majority (98.7\%) of port patients had the port needle changed weekly. Needle changes were carried out by the provider's staff in $56.7 \%$ of the port patients, by outpatient nursing personnel in $25.1 \%$, by the attending physician in $16.9 \%$, and by the patient himself or a relative in $1.3 \%$ of the cases. Dressing changes were managed similarly. $72.8 \%$ of the patients had weekly changes, in $40.1 \%$ carried out by the provider's staff, in $46.6 \%$ by outpatient nursing personnel, in $9.6 \%$ by the attending physician, and in $3.7 \%$ by the patient or a relative.

In $55.9 \%$ of the patients, the CVC was used for HPN only. 376 (78.2\%) patients received the HPN 7 days per week, 65 (13.5\%) had 5-6, and 38 (7.9\%) 1-4 infusions per week. In $2(0.4 \%)$ patients, data were not available. The daily connecting procedures, including the admixture of vitamins and trace elements, were carried out by outpatient nursing personnel $(74.4 \%)$, the patient or a relative $(14.8 \%)$, the attending physi-
Table 2. Incidence of central venous catheter complications

\begin{tabular}{|c|c|c|c|}
\hline & Patients, $\mathrm{n}$ & $\begin{array}{l}\text { Incidence } / 1,000 \\
\text { catheter days }\end{array}$ & $95 \% \mathrm{CI}$ \\
\hline Complications & 63 & 2.01 & $1.55-2.57$ \\
\hline \multicolumn{4}{|l|}{ Infections } \\
\hline Total & 32 & 1.02 & $0.70-1.44$ \\
\hline Local & 15 & 0.48 & $0.27-0.79$ \\
\hline Systemic & 17 & 0.54 & $0.32-0.87$ \\
\hline Obstructions & 11 & 0.35 & $0.18-0.63$ \\
\hline Dislocations & 2 & 0.06 & $0.01-0.23$ \\
\hline Defects & 4 & 0.13 & $0.04-0.33$ \\
\hline Other & 14 & 0.45 & $0.24-0.75$ \\
\hline Explantations ${ }^{\mathrm{a}}$ & 12 & 0.38 & $0.20-0.67$ \\
\hline
\end{tabular}

a 7 due to systemic infection, 2 due to obstruction, 2 due to other complications, 1 due to local infection and obstruction.

cian $(7.7 \%)$, or the provider's staff $(3.1 \%)$. The infusion was administered per gravitational force line $(86.5 \%)$ or infusion pump $(13.5 \%)$.

\section{Complications}

In the course of 31,337 catheter days, $63 \mathrm{CVC}$ complications were observed in $52(10.8 \%)$ of the 481 patients, leading to 12 catheter removals. Half of the complications (50.8\%) were infections, $27.0 \%$ systemic (with/without local), and $23.8 \%$ local ones. Furthermore, $17.5 \%$ of complications were catheter obstructions, $3.2 \%$ catheter dislocations, $6.3 \%$ other catheter defects, and $22.2 \%$ other complications. So, in total, incidence of complications was 2.01 per 1,000 catheter days, including 1.02 infections per 1,000 catheter days (table 2). None of the complications were fatal. Because of the relatively low number of complications, the exploratory analyses failed to identify potential risk factors.

\section{Discussion}

The objective of this pilot study was to provide incidence estimates of CVC-related complications in everyday HPN patient care under the conditions of the German healthcare system. During the observational period, an incidence of $2.01 \mathrm{CVC}$ related complications per 1,000 catheter days and of 1.02 CVC-related infections were documented. Infections were the most frequent CVC complications (50.8\%), followed by CVC occlusions (17.5\%) and other CVC defects (6.3\%).

These figures agree well with results of recently published studies [8-21] which reported incidences of 0.94-5.56 catheter complications per 1,000 catheter days and $0.60-5.36$ catheter infections per 1,000 catheter days, but some differences have to be considered. Most of the previous publications were based on retrospective data, without a defined observational plan: only 4 of them [9-12] were prospective studies. They re- 
ported incidences of $0.82-3.86$ catheter infections per 1,000 catheter days whereas only one [9] reported an overall incidence of CVC complications (5.56/1,000 catheter days). Moreover, the majority of publications reported on series from single centres with specialised expertise in HPN [9-11, 14-18]. They documented the expert standard of specialised centres that may not be generalisable to the setting of everyday care provided by general practitioners and unspecialised outpatient nursing services. Less is known about nationwide care of HPN patients provided by heterogeneous centres. Ireton-Jones and DeLegge [19] published more recent US data from 1997-2001 by using the database of one nutrition support provider. Analysing these data retrospectively, the authors calculated an incidence of 0.66 catheter infections per 1,000 catheter days (95\% CI 0.59-0.74). Similar results were found by Baxter and McKee [12] in their audit of the Scottish Home Parenteral Nutrition Managed Clinical Network (0.9 catheter infections per 1,000 catheter days; $95 \%$ CI $0.45-1.57)$.

The underlying disease may affect the incidence of CVCrelated complications. As shown in some studies [8, 20], the occurrence of catheter complications was significantly lower in patients with malignancies than with benign disease. Since our data are based on a sample of $90.7 \%$ patients with malignancies, they should be comparable to those found in studies with a high percentage of oncological patients. These studies $[8,16$, $18,20]$ reported CVC-related infections of 0.60-5.36 infections per 1,000 catheter days, where 3 of them found lower $[8,20]$ or similar [18] incidences compared to our estimate of 1.02 infections per 1,000 catheter days.

Even the type of catheter has been discussed as risk factor for CVC-related complications. Whereas some studies [10, 20] found no difference in the incidence of CVC-related infections between the externally tunnelled type of CVC (Hickman/Broviac) and the implanted (Port-a-cath) type, others reported a significantly lower incidence in patients with externally tunnelled systems $[8,16]$ or with implanted port catheters [21]. Seeing these heterogeneous results and classifying the very high percentage of port patients in our study $(94.4 \%)$ as a German peculiarity, the discussion of this aspect is quite difficult. Indeed, the incidence of CVC-related infections found in a sample with $69.27 \%$ port patients [16] was considerable higher than our one. But one of the authors' main conclusions was that training and experience were likely to reduce CVC-related infections. So, the lower-risk type of catheter should not be discussed without including the intensity and quality of education and experience in the daily connecting procedure. But even if the occurrence of CVC-related complications is influenced by a multitude of risk factors, such as the underlying disease, the type of catheter, education and experience in the daily connecting procedure, frequency of infusions, or use of the catheter for other reasons, in our study none of these parameters could be identified as an independent risk factor.

Despite the fact that, as mentioned above, this trial is a prospective evaluation with predefined and quality-assured investigational instruments, there are still methodological limitations. The restriction to patients with more than 10 infusion days may have led to overly optimistic incidence estimates. However, our rationale was to exclude patients with HPN administered only during their very last days of life, and for whom guidelines actually do not recommend HPN [5]. Another aspect is that only $70 \%$ of the patients gave their consent to telephone interviews. In $41 \%$ of the patients, the attending physicians and/or nurses actually took part in a telephone interview. Complication rates in the group with telephone interviews were higher than in patients without. Possible explanations are false-positive findings due to oversensitivity and questionable specificity of data collection by telephone (leading to overestimates), or underreporting of complications in the non-telephone interview group, or both.

Nevertheless, this pilot study with its innovative study design is the first step in the development of further studies that lead to the implementation and evaluation of quality standards to maximise excellent patient care and minimise complications and unnecessary costs in consequence of inadequate medical and outpatient care and hospital re-admissions [23]. In response to the limitations of the present study, further studies with data collection from patients of multiple HPN service providers, improved quality control, and $100 \%$ corroboration of suspected cases by means of unstructured expert interviews are needed. They should describe a reasonable risk-benefit and cost-benefit ratio in a group of severely ill patients with advanced cancer in the majority of cases, and be able to establish a nationwide high-quality standard.

\section{References}

1 Waitzberg DL, Caiaffa WT, Corrieia MIDT: Hospital malnutrition: the Brazilian National Survey (IBRANUTRI): a study of 4000 patients. Nutrition 2001;17:573-580.

2 Persson C, Sjöden, PO, Glimelius B: The Swedish version of the patient-generated global assessment of nutritional status: gastrointestinal vs. urological cancers. Clin Nutr 1999;18:71-77.

3 Norman K, Lochs H, Pirlich M: Malnutrition as a prognostic factor. Chir Gastroenterol 2001;20:175180
4 Pirlich M, Schuetz T, Norman K, Gastell S, Lübke HJ, Bischoff SC, Bolder U, Frieling T, Gueldenzoph H, Hahn K, Jauch KW, Schindler K, Stein J, Volkert D, Weimann A, Werner H, Wolf C, Zuercher G, Bauer P, Lochs H: The German hospital malnutrition study. Clin Nutr 2006;25:563-572.

5 Arends J, Zuercher G, Dossett A, Fietkau R, Hug MJ, Schmid I, Shang E, Zander R: Nichtchirurgische Onkologie. Aktuel Ernaehr Med 2007;32 (suppl 1):S124-S133.
6 Kemp L, Burge J, Choban P, Harden J, Mirtallo J, Flancbaum L: The effect of catheter type and site on the infection rates in total parenteral nutrition patients. J Parenter Enteral Nutr 1994;18:71-74.

7 Bijma R, Girbes AR, Kleijer DJ, Zwaveling JH: Preventing ventral venous catheter-related infection in a surgical intensive-care unit. Infect Control Hosp Epidemiol 1999;20:618-620. 
8 Bozzetti F, Mariani L, Boggio Bertinet D, Chiavenna G, Crose N, De Cicco M, Gigli G, Micklewright A, Moreno Villares JM, Orban A, Pertkiewicz M, Pironi L, Planas Vilas M, Prins F, Thul P, ESPENHAN Working Group: Central venous catheter complications in 337 patients on home parenteral nutrition: an analysis of over 100,000 catheter days. Clin Nutr 2002;21:475-485.

9 De Burgoa LJ, Seidner D, Hamilton C, Stafford J, Steiger E: Examination of factors that lead to complications for new home parenteral nutrition patients. J Infus Nurs 2006;29:74-80.

10 Reimund JM, Arondek Y, Finck G, Zimmerman F, Duclos B, Baumann R: Catheter-related infection in patients on home parenteral nutrition: results of a prospective survey. Clin Nutr 2002;21:33-38.

11 Pironi L, Paganelli F, Labate AMM, Merli C, Guidtti C, Spinucci G, Miglioli M: Safety and efficacy of home parentral nutrition for chronic intestinal failure: a 16-year experience at a single centre. Dig Liver Dis 2003;35:314-324.

12 Baxter JP, McKee RF: The Scottish home parenteral nutrition managed clinical network: one year on. Clin Nutr 2003;22:501-504.
13 Van Gossum A, Vahedi K, Abdel-Malik, Staun M, Pertkiewicz M, Shaffer J, Hebuterne X, Beau P, Guedon C, Schmit A, Tjellesen L, Messing B, Forbes A, ESPENHAN Working Group: Clinical, social and rehabilitation status of long-term home parenteral nutrition patients: results of a European multicentre survey. Clin Nutr 2001;20:205-210.

14 Knafelz D, Gambarara M, Diamanti A, Papadatou B, Ferretti F, Tarissi De Iacobis I, Castro M: Complications of home parenteral nutrition in a large pediatric series. Transplant Proc 2003;35:3050-3051.

15 Freshwater DA, Saadeddin A, Deel-Smith P, Digger T, Jones BJM: Can home parenteral nutrition be provided by non-specialised centres? 2,300 weeks of experience at a district general hospital in the United Kingdom. Cli Nutr 2005;24:229-235.

16 Santarpia L, Pasanisi F, Alfonsi L, Violante G, Tiseo D, De Simone G, Contaldo F: Prevention and treatment of implanted central venous catheter (CVC)related sepsis: a report after six years of home parenteral nutrition (HPN). Clin Nutr 2002;21:207-211.

17 Colomb V, Fabeiro M, Dabbas M, Goulet O, Merckx J, Riccour C: Central venous catheter-related infections in children on long-term home parenteral nutrition: incidence and risk factors. Clin Nutr 200;19:355-359.
18 Hoda D, Jatoi A, Burnes J, Loprinzi C, Kelly D: Should patients with advanced, incurable cancers ever be sent home with total parenteral nutrition? Cancer 2005;103:863-868.

19 Ireton-Jones C, DeLegge M: Home parenteral nutrition registry: a five-year retrospective evaluation of outcomes of patients receiving home parenteral nutrition support. Nutr 2005;21:156-160.

20 Shirotani N, Iino T; Numata K, Kameoka S: Complications of central venous catheters in patients on home parenteral nutrition: an analysis of 68 patients over 16 years. Surg Today 2006;36:420-424.

21 Howard L, Ashley C: Management of complications in patients receiving home parenteral nutrition. Gastroenterology 2003;124:1651-1661.

22 Koletzko B, Jauch KW, Krohn K, Verwied-Jorky S für die Arbeitsgruppe Parenterale Ernährung der DGEM: Leitlinie Parenterale Ernährung der Deutschen Gesellschaft für Ernährungsmedizin e.V. (DGEM). Aktuel Ernaehr Med 2007;32(suppl 1): S1-S134.

23 Bischoff SC, Kester L, Meier R, Raziwill R, Schwab B, Thul P: Organisation, Verordnung, Zubereitung und Logistik der parenteralen Ernährung im Krankenhaus und zu Hause; die Rolle von Ernährungsteams. Aktuel Ernaehr Med 2007;32 (suppl 1):S35-S40. 